\title{
Molecular detection of Rickettsia species and host associations of Laelaps mites (Acari: Laelapidae) in Taiwan
}

\author{
Chi-Chien Kuo ${ }^{1} \cdot$ Pei-Lung Lee ${ }^{2} \cdot$ Hsi-Chieh Wang ${ }^{2,3}$ (D) \\ Received: 3 December 2019 / Accepted: 30 June 2020 / Published online: 9 July 2020 \\ (c) Springer Nature Switzerland AG 2020
}

\begin{abstract}
Various rickettsiae have recently been detected in Laelaps mites (Acari: Laelapidae), which are common ectoparasites of rodents; however, investigations on this topic remain very scarce, particularly in Asia. In the present study, shrews and rodents were trapped from 2006 to 2010 in eight lowland regions of Taiwan $(<500 \mathrm{~m}$ in elevation) to collect associated Laelaps mites, from which Rickettsia - a group of emerging pathogens-were detected and identified by assaying the gltA and $\operatorname{ompB}$ genes. A total of 853 Laelaps mites of at least four species were collected from a sample of 1004 small mammals that included one shrew and 10 rodent species. Rattus losea was the most common species $(44.9 \%$ of total hosts) and hosted the highest percentage of mites (76.6\% of total mites). Laelaps nuttalli was the most abundant mite species (51.7\% of total mites), followed by Laelaps echidninus (24.2\%), Laelaps sedlaceki (23.1\%), and Laelaps myonyssognathus (0.2\%). Notably, Rickettsia species with the highest similarity to spotted fever group (SFG) rickettsiae were identified from seven of the 72 pools of Laelaps mites. The presence of SFG rickettsiae in hematophagous Laelaps mites, particularly including species that are closely associated with commensal rodents in frequent contact with humans, calls for further investigation on the competence of Laelaps mites in transmitting rickettsiae.
\end{abstract}

Keywords Vector-borne diseases $\cdot$ Host-parasite association $\cdot$ Laelapine mite $\cdot$ Small mammals

\section{Introduction}

Small mammals, including rodents and shrews, are typically infested with a variety of ectoparasites, including fleas, lice, mites, and ticks. Some of these ectoparasites are capable of transmitting causative agents of diseases to humans, with these being more

Hsi-Chieh Wang

sjwang1019@gmail.com

1 Department of Life Science, National Taiwan Normal University, Taipei, Taiwan

2 Center for Diagnostics and Vaccine Development, Centers for Disease Control, Ministry of Health and Welfare, Taipei, Taiwan

3 Institute of Environmental and Occupational Health Sciences, College of Public Health, National Taiwan University, Taipei, Taiwan 
thoroughly studied by researchers. Most prominent among these are hard ticks (Acari: Ixodidae), which can transmit human diseases such as anaplasmosis, babesiosis, Lyme borreliosis, spotted fever, and tick-borne encephalitis (Dantas-Torres et al. 2012). Fleas also receive great attention for their central role as vectors of Bartonella, flea-borne spotted fever, murine typhus, and plague (Bitam et al. 2010). In comparison, the potential role of mites (Acari) in transmitting diseases remains relatively understudied (Reeves et al. 2006) and most research has been focused on rickettsialpox (caused by Rickettsia akari Huebner) and scrub typhus (caused by Orientia tsutsugamushi Tamura et al.) that are transmitted by the house mouse mite (Liponyssoides sanguineus Hirst, Dermanyssidae) and chigger mites (Trombiculidae), respectively (Elliott et al. 2019; Paddock 2020).

Mites of the genus Laelaps (Mesostigmata: Laelapidae) are common ectoparasites of small mammals, particularly rodents (Jameson 1965). Although some neotropical laelapines might not feed on blood (Martins-Hatano et al. 2002), other species such as Laelaps echidninus and Laelaps nuttalli are hematophagous parasites of humans and rodents (Wharton and Cross 1957; Jameson 1965; Krantz and Walter 2009) that might be capable of transmitting diseases among wild animals and humans (Wharton and Cross 1957; Valiente Moro et al. 2005). However, studies on Laelaps mites and their role as disease vectors remain very limited, despite some rickettsiae having recently been detected (though vector competence in pathogen transmission was not demonstrated) in Laelaps mites. These included Anaplasma platys and Anaplasma phagocytophilum in Laelaps spp. (Reeves et al. 2006), and Rickettsia helvetica and Rickettsia felis in Laelaps agilis (Mitková et al. 2015; Radzijevskaja et al. 2018).

Notably, studies of Laelaps mites in Taiwan remain scarce. The only research that has focused on this group of ectoparasites in Taiwan listed the rodent host and geographic occurrence of eight Laelaps species (Jameson 1965). Tsai et al. (2010) identified Bartonella species in shrews and rodents trapped near animal farms and their associated fleas and lice in Taiwan but did not detect Bartonella in 38 adult L. echidninus and 41 pools of nymphal Laelaps mites. Related studies in other Asian countries are also fragmentary. The host associations of Laelaps mites have been documented in Asiatic Russia (Vinarski and Korallo-Vinarskaya 2016), Bangladesh (Fuehrer et al. 2012), China (Guo et al. 2013), Indonesia (Durden and Page 1991), Laos and Vietnam (Allred 1970), and Malaysia (Ahamad et al. 2013).

Spotted fever group (SFG) rickettsioses are transmitted by ectoparasites infective of Rickettsia species. Hard ticks are the primary vectors, though some Rickettsia species are also transmitted by fleas and mites (Raoult and Roux 1997; Parola et al. 2005). Recent decades have witnessed the emergence of many novel Rickettsia species, whereas human cases of SFG rickettsioses have continuously appeared in previously unrecognized regions (Raoult and Roux 1997; Perlman et al. 2006; Parola et al. 2013).

Although Rickettsia species have previously been identified in Laelaps mites (Mitková et al. 2015; Radzijevskaja et al. 2018), similar investigations remain scarce, particularly in Asia. Tay et al. (2014) had attempted but failed to detect rickettsiae in Laelaps mites in Malaysia. The first aim of the present study was to detect Rickettsia-related species in Laelaps mites in Taiwan to assess their potential significance for transmitting rickettsiae. Moreover, knowledge regarding the relative contribution of distinct host species in supporting parasites is fundamental for disease mitigation by controlling certain hosts; therefore, the secondary aim of this study was to systematically investigate and compare the extent of Laelaps mite infestation among small mammal hosts in different parts of Taiwan. To our knowledge, this is the first study to detect Rickettsia in Laelaps mites in Taiwan while also systematically assessing their hosts. Importantly, the results of this study will 
contribute to the general understanding of Laelaps mites and their potential importance as disease vectors.

\section{Materials and methods}

\section{Small mammal trapping and collection of mites}

This present study was part of a research effort to investigate Rickettsia infections in small mammals and associated ectoparasites in rural lowland Taiwan $(<500 \mathrm{~m}$ in elevation, Kuo et al. 2015a, b; Wang et al. 2020; for more details on the trapping and handling of small mammals in this study, refer to Kuo et al. 2015a). Briefly, from 2006 to 2010, small mammals (shrews and rodents) were trapped at three counties in eastern Taiwan (Yilan: $121.7378^{\circ} \mathrm{E}, 24.7021^{\circ} \mathrm{N}$; Hualien: $121.6112^{\circ} \mathrm{E}, 23.9911^{\circ} \mathrm{N}$; Taitung: $121.1438^{\circ} \mathrm{E}$, $22.7613^{\circ} \mathrm{N}$ ), three counties in western Taiwan (Taoyuan: $121.2300^{\circ} \mathrm{E}, 24.9554^{\circ} \mathrm{N}$; Taichung: $120.6736^{\circ}$ E, $24.1477^{\circ} \mathrm{N}$; Kaoping: $120.3014^{\circ}$ E, $22.6273^{\circ} \mathrm{N}$ ), and two counties located in Taiwan's offshore islets (Kinmen: $118.4171^{\circ} \mathrm{E}, 24.4414^{\circ} \mathrm{N}$, Penghu: $119.5833^{\circ}$ E, $\left.23.5833^{\circ} \mathrm{N}\right)$ (Fig. 1). In each county, 80 Sherman traps $(26.5 \times 10 \times 8.5 \mathrm{~cm})$ and 80 mesh traps $(27 \times 16 \times 13 \mathrm{~cm})$ were deployed in agricultural fields or rural villages for at

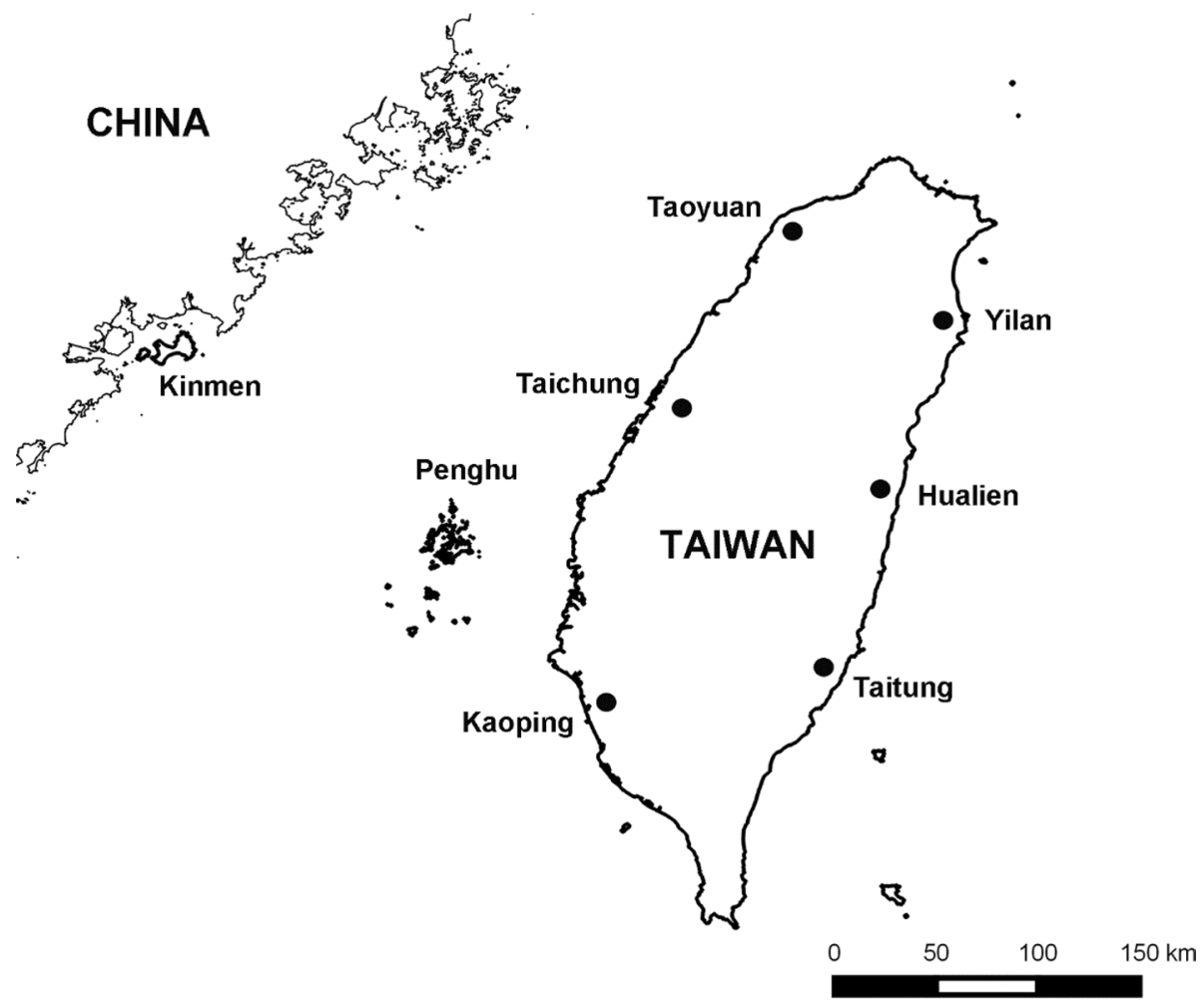

Fig. 1 Study sites for the trapping of shrews and rodents and collecting of associated Laelaps mites (Acari: Laelapidae) in lowland Taiwan from 2006 to 2010 
least two different seasons (spring: March to May; summer: June to August; fall: September to November; winter: December to February) and baited with sweet potato smeared with peanut butter. Trapped small mammals were euthanized with an overdose of Zoletil 50 (Virbac SA, Carros, France). Laelaps mites were brushed off from hosts above a plastic pan until no mites could be found and collected with forceps, then preserved in $70 \%$ ethanol and stored at $-70{ }^{\circ} \mathrm{C}$ for subsequent molecular investigation. Small mammals and Laelaps mites were morphologically identified to species following Lin (1980) and Jameson (1965), respectively.

\section{Detection of Rickettsia species in mites}

Laelaps mites were pooled for the detection of Rickettsia, with each pool containing five mites that typically belong to the same species and were collected from the same host individual. If this could not be achieved, mites of different species or from different host individuals were combined for a pool of five mites (approximately $20 \%$ of samples). For each county, mites of all present species were included in the assay except for one mite species with only two individuals, and each county included up to 10 pools. Mite DNA was extracted using a QIAamp DNA Mini Kit (Qiagen, Hilden, Germany) after sterilized mite specimens were ground in a solution containing $180 \mathrm{ml} \mathrm{SPG}$ buffer $\left[3.0 \mathrm{mM} \mathrm{KH} \mathrm{PO}_{4}\right.$ (Merck), $7.2 \mathrm{mM} \mathrm{K}_{2} \mathrm{HPO}_{4}$ (Merck), $40 \mathrm{mM}$ L-glutamic acid (Sigma), $218 \mathrm{mM}$ sucrose (Sigma)] and $20 \mathrm{ml}$ proteinase $\mathrm{K}$ (Sigma), and vortexed at $56{ }^{\circ} \mathrm{C}$ overnight. Mites were detected of Rickettsia presence with nested polymerase chain reaction (PCR) following Kuo et al. (2015a), which targeted the genes encoding the 120- to $135-\mathrm{kDa}$ outer membrane protein B (ompB; outer primer pair: ompB OF, 5'-GTA ACC GGA AGT AAT CGT TTC GTA A-3'; ompB OR, 5'-GCT TTA TAA CCA GCT AAA CCA CC-3'; inner primer pair: ompB SFG IF, 5'- GTT TAA TAC GTG CTG CTA ACC AA-3'; ompB SFG/TG IR, 5'- GGT TTG GCC CAT ATA CCA TAA G-3'; ompB TG IF, 5'-AAG ATC CTT CTG ATG TTG CAA CA-3'; 426 bp) and citrate synthase ( $g l t A$; outer primer pair: RpCS.877p, 5'-GGG GGC CTG CTC ACG GCG G-3'; RpCS.1258n, 5'-AAT GCA AAA AGT ACA GTG AAC A-3'; inner primer pair: RpCS.896, 5'-GGC TAA TGA AGC AGT GAT AA-3'; RpCS.1233n, 5'-GCG ACG GTA TAC CCA TAG C-3'; 338 bp). Laboratory Rickettsia rickettsii DNA and DEPC-treated water were used as positive and negative controls, respectively. $R$. rickettsii DNA was prepared from $R$. rickettsii antigens coated in a $R$. rickettsii IFA substrate slide (product code IF0101; Focus Technologies) and extracted using a QIAamp DNA Mini Kit. Samples were deemed positive for Rickettsia presence when either the $\operatorname{ompB}$ or gltA gene was detected. Rickettsia species in positive samples were identified by purifying the PCR products using a QIAquick Gel Extraction Kit and then sequencing once in each direction. The sequencing was performed by a commercial company (Mission Biotech, Taipei, Taiwan). DNA nucleotide sequences were assessed using the Basic Local Alignment Search Tool (http://www.ncbi.nlm.nih.gov) for any resemblance to known Rickettsia species. However, due to the limited number of genes detected and the very small fragments sequenced, only broad category of rickettsiae (e.g. SFG rickettsiae) instead of precise Rickettsia species was reported in this study.

\section{Data analysis}

The difference in mite load (mean mites per host individual) among host species, study sites, and seasons was investigated with a negative binomial generalized linear model 
(NBGLM) to account for overdispersion of data, and a significant difference was evaluated based on the $95 \%$ Wald confidence interval. These procedures were implemented in SPSS Statistics v.19.0 (IBM Corporation). We used EpiTools Epidemiological Calculators (Sergeant 2018) to estimate mean and 95\% confidence interval (CI) of individual-level (per mite) prevalence of Rickettsia infection in mites with a frequentist approach assuming perfect test, with confidence intervals calculated based on binomial theory following Cowling et al. (1999).

\section{Results}

\section{Host association of Laelaps mites}

We captured a total of 1,004 small mammals that included one shrew and ten rodent species (Table 1). The most common species was Rattus losea (44.9\% of total mammals captured), followed by Suncus murinus (21.1\%) and Mus caroli (13.3\%). Rattus losea also hosted the highest percentage of mites ( $76.6 \%$ of total mites), followed by M. caroli $(11.5 \%)$, whereas only $0.8 \%$ of mites were collected from $S$. murinus despite the commonness of this shrew species (Table 1). Upon excluding the non-representative Niviventer coninga due to its small sample size (two individuals), the exotic Rattus exulans exhibited a higher mite load (an average of 1.76 mites per individual) than most other species except for Rattus norvegicus (mean =1.70), R. losea (1.45), and M. caroli (0.73) (NBGLM, all $P<0.05)$. Among all host species, $R$. exulans also had a higher prevalence of infestation $(52.0 \%)$ (Table 1$)$.

\section{Laelaps mite fauna and geographical and seasonal variation}

A total of 853 Laelaps mites of at least four species were collected (Table 2). Laelaps nuttalli was the most abundant species, constituting over half of the collected mites (51.7\%). This species was followed by equally abundant L. echidninus and Laelaps sedlaceki, each accounting for approximately one-quarter of the mites (24.2 and $23.1 \%$, respectively). In contrast, Laelaps myonyssognathus was rare, with only two individuals collected $(0.2 \%)$. The three most common species (L. echidninus, L. nuttalli, and L. sedlaceki) can be found on most small mammal species (seven, nine, and six, respectively), whereas L. myonyssognathus was only collected from $R$. losea (Table 1).

Geographically, L. nuttalli and L. echidninus were generally common in different parts of Taiwan. On the other hand, L. sedlaceki occurred mainly on the main island of Taiwan and was uncommon on offshore islets. Moreover, the rare L. myonyssognathus was observed in western Taiwan only (Table 2 ). The mite load on $R$. losea, the primary small mammal host, varied considerably among regions (NBGLM, Wald's $\chi^{2}=86.4, P<0.001$; range 0.43 to 3.05$)$, with lower loads occurring in Yilan $($ mean $=0.43)$ in eastern Taiwan and Kaoping (0.59) in western Taiwan (all $P<0.05$ ) (Table 2). There was also a seasonal variation in mite load on $R$. losea (NBGLM, Wald's $\chi^{2}=17.5, P<0.005$ ), with higher and lower loads in the fall (mean=2.04) and winter (0.62), respectively (Fig. 2a). Likewise, load of L. echidninus and L. nuttalli was generally higher and lower in the fall and winter, respectively (Fig. 2b, c); however, load of $L$. sedlaceki was higher in the spring but lower in the fall (Fig. 2d). 


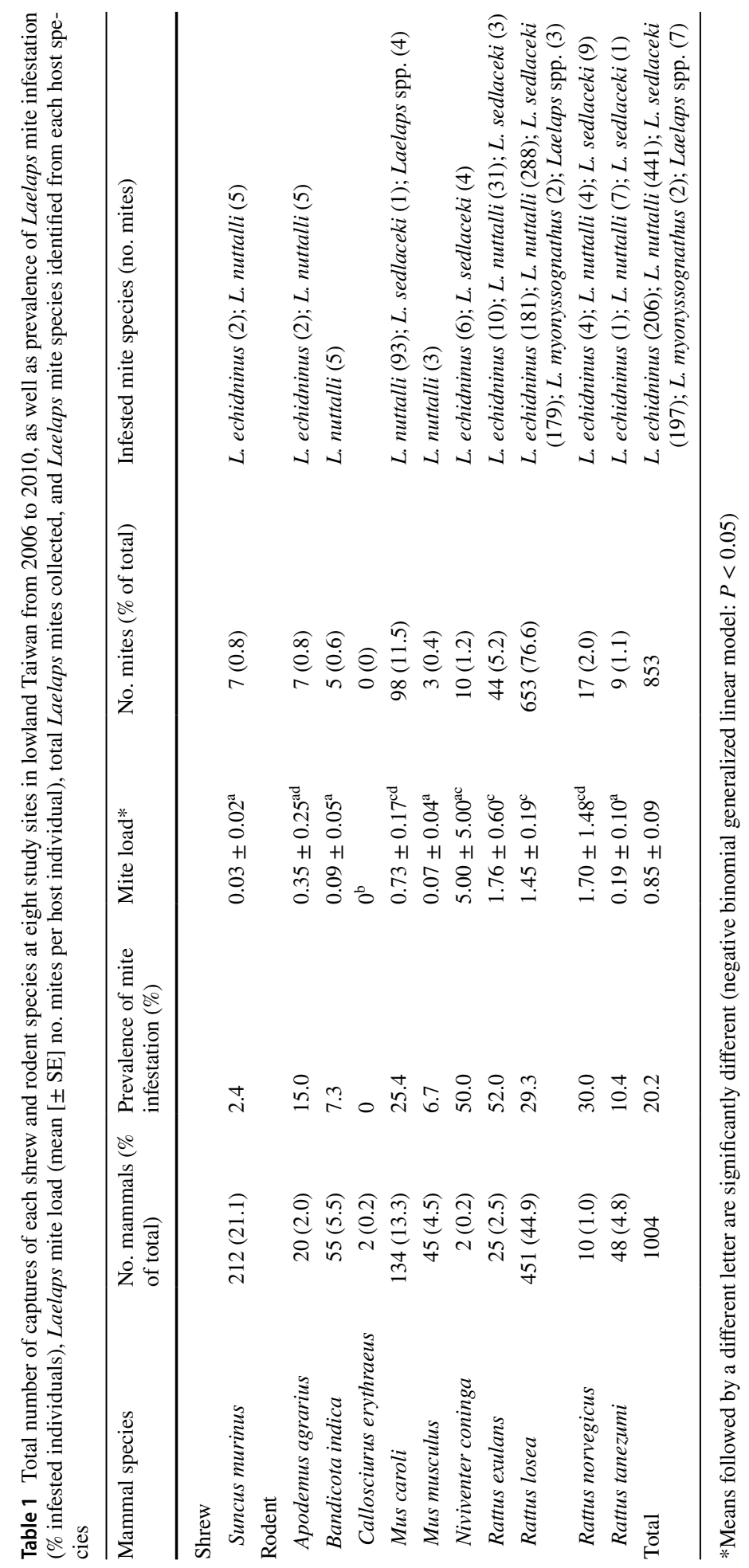




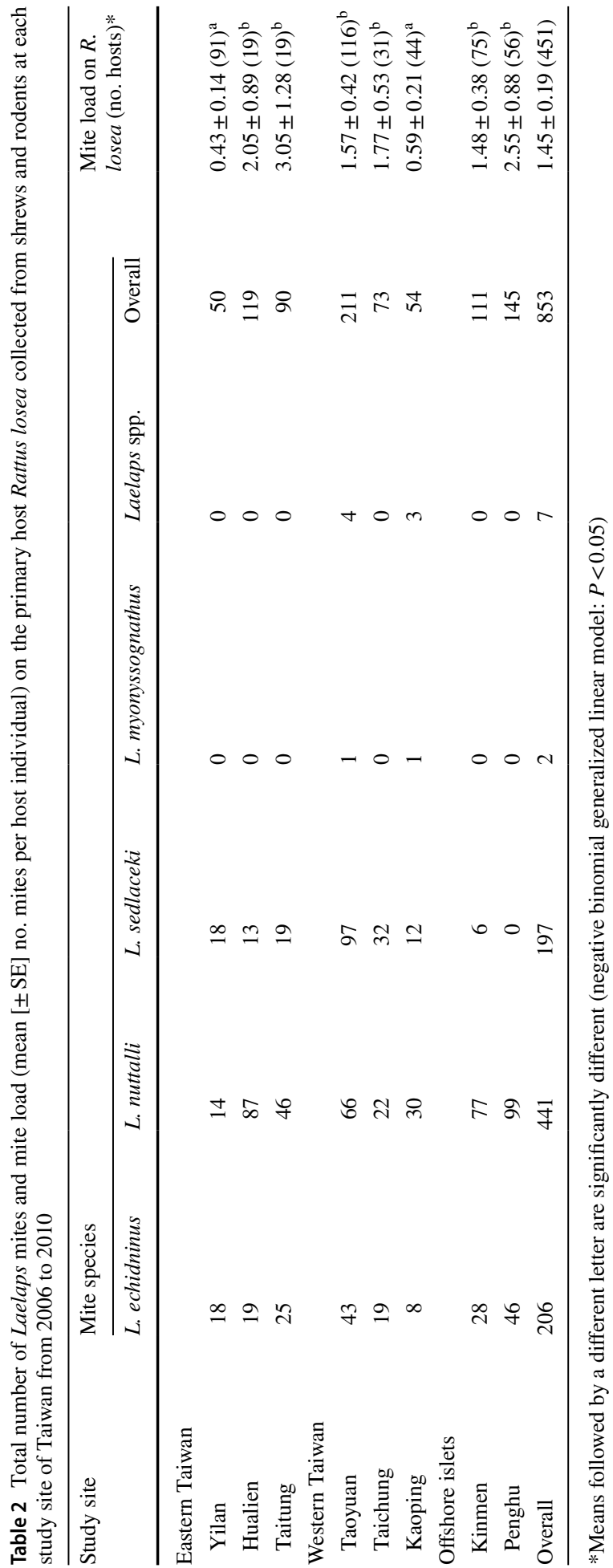



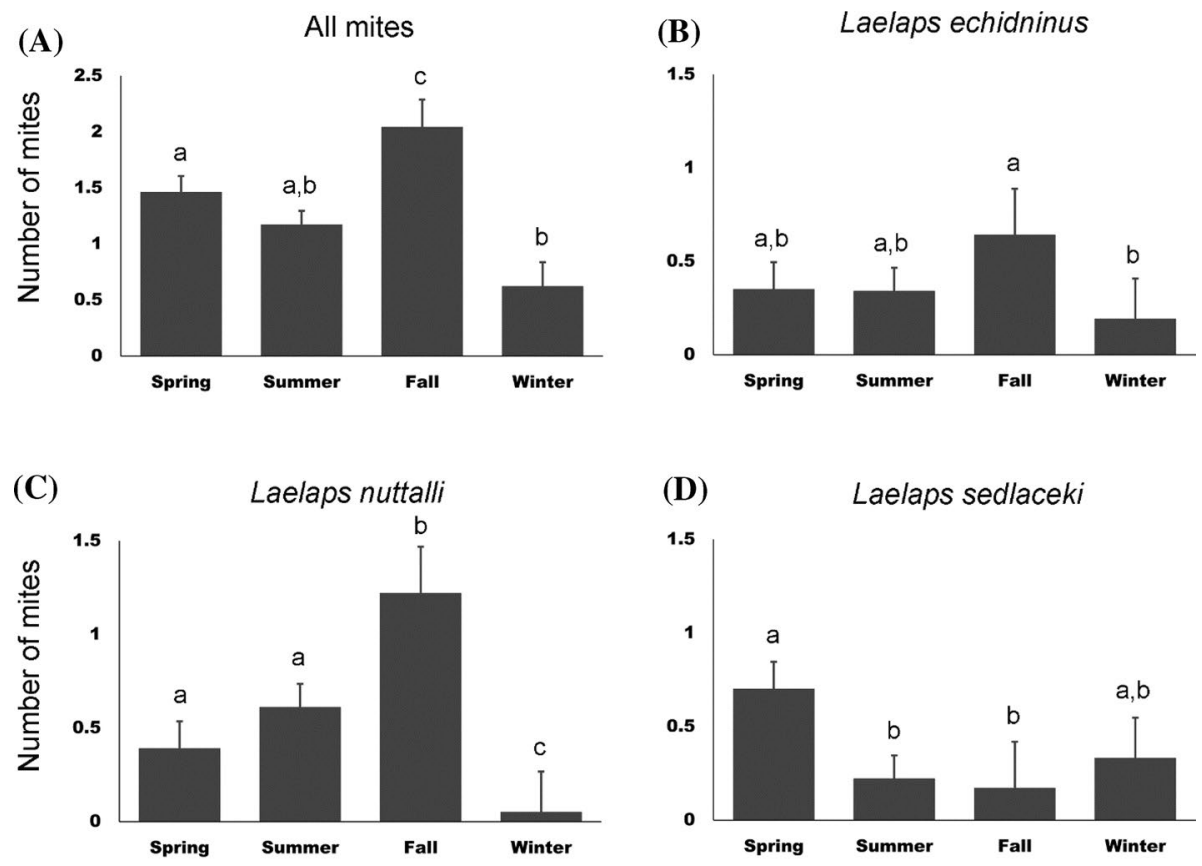

Season

Season

Fig. 2 Seasonal difference in the mean $(+\mathrm{SE})$ number of Laelaps mites collected from Rattus losea in lowland Taiwan from 2006 to 2010. a Mites of all species; b Laelaps echidninus; c Laelaps nuttalli; d Laelaps sedlaceki. Means within a panel capped with different letters are significantly different, based on the $95 \%$ Wald confidence interval

\section{Detection of Rickettsia in Laelaps mites}

In total 72 pools of Laelaps mites were examined for the presence of Rickettsia. The positivity rates per pool were 4.2 and $9.7 \%$ based on the $\mathrm{ompB}$ and gltA genes, respectively (Table 3), whereas positivity rates per mite were $0.85 \%$ (95\% CI $0.17-2.46 \%)$ and $2.02 \%(0.81-4.13 \%)$, respectively. The positivity rate was higher in Taoyuan and Penghu for the $о т p B$ gene, and it was higher in Hualien, Taitung, and Kinmen for the gltA gene. For the $o m p B$ gene, three DNA sequences that matched the closest in GenBank (99.0-99.2\% similarity) to SFG rickettsiae were each detected from L. echidninus, L. sedlaceki, and a pool of L. echidninus and L. nuttalli (GenBank Accession Numbers MT611477-MT611479); for the gltA gene, four sequences with the highest similarity to SFG rickettsiae (99.3-100\% similarity) were each detected from L. echidninus, L. nuttalli (2×), and L. sedlaceki (MT611473-MT611476) (Table 3). All of the mites with Rickettsia species detected were collected from $R$. losea. 


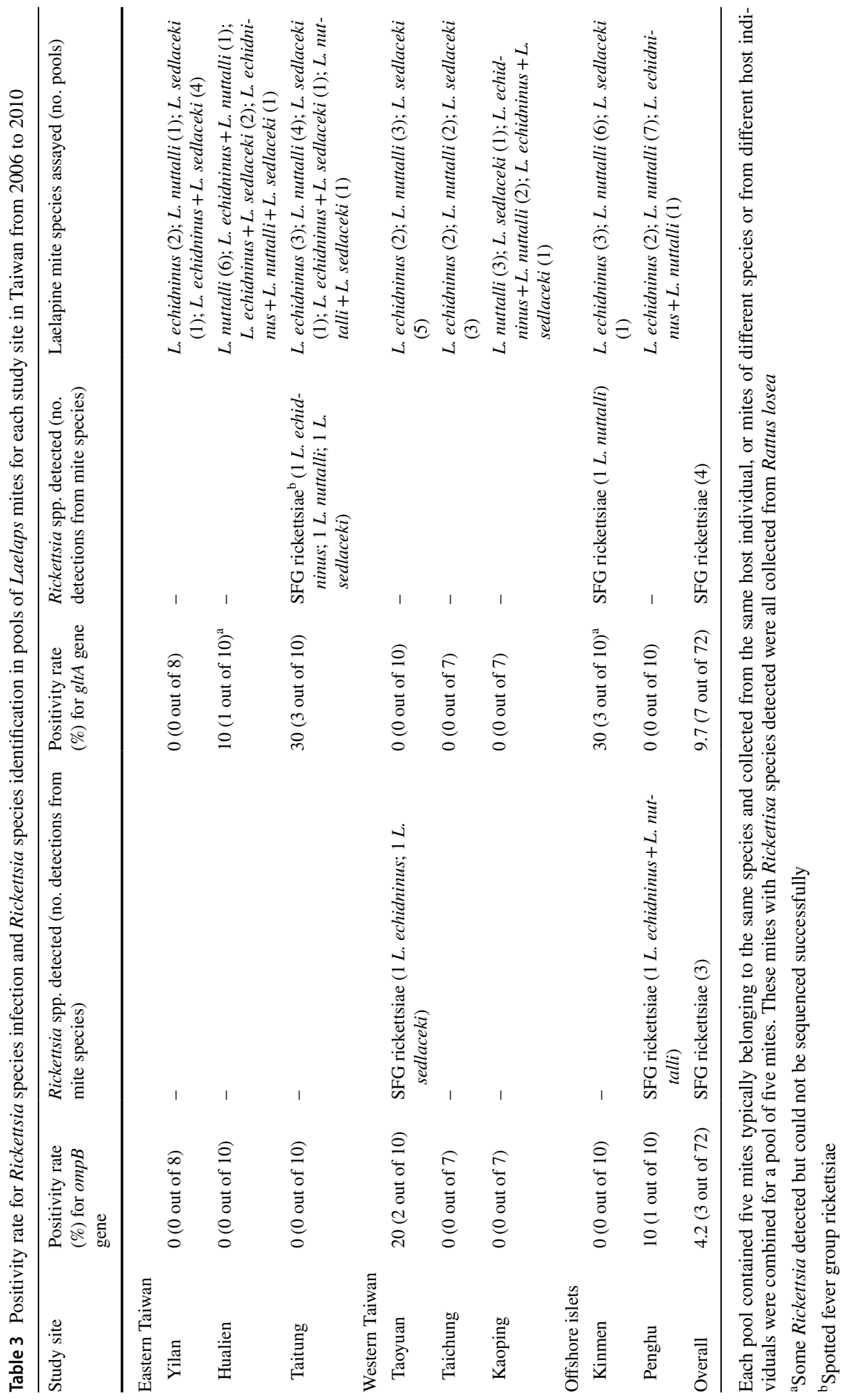




\section{Discussion}

In addition to the $R$. felis and $R$. helvetica that were detected in L. agilis in Europe (Mitková et al. 2015; Radzijevskaja et al. 2018), we identified Rickettsia species closely related to the SFG rickettsiae in Laelaps mites for the first time in Asia. Moreover, these Rickettsia species were largely detected in L. echidninus and L. nuttalli, which are known to bite humans (Wharton and Cross 1957). However, due to that only fragments of gltA and $\mathrm{ompB}$ genes were identified, further definitive confirmation of Rickettsia species is required. Additionally, SFG rickettsiae are primarily transmitted by ticks (Parola et al. 2013). Therefore, it is more likely that the rickettsiae detected in the present study were contained in blood meals ingested by the mites rather than mites being infective and capable of transmitting these pathogens. For example, prevalence of Rickettsia infection in the small mammal hosts during our parallel studies on Rickettsia detection in Taiwan was high (Kuo et al. 2015a) although these Rickettsia-positive mites were not derived from the same small mammal hosts examined for the presence of Rickettsia. The non-concordance in detection of SFG rickettsiae based on $g l t A$ and $о m p B$ genes, respectively, also suggests that the concentration of rickettsiae in these mites might be too low for successful amplification by both gene targets simultaneously. In this context, it cannot be excluded that Laelaps mites might define alternative transmission routes for some of these Rickettsia species. For example, although fleas are the primary competent vectors of $R$. felis, this pathogen can also be successfully cultivated in tick and mosquito-derived cell lines (Reif and Macaluso 2009). Therefore, the presence of tick-borne rickettsiae warrants further investigation on the competence of hematophagous Laelaps mites in transmitting Rickettsia species, which has never been investigated to date.

A total of eight Laelaps mite species have previously been recorded in Taiwan (Jameson 1965). These include the four species that were also collected for the present study in lowland areas (<500 $\mathrm{m}$ in elevation; Laelaps prognathous in Jameson (1965) considered a junior synonym of L. myonyssognathus by Mitchell (1968)). The other four species ( $L$. agilis, Laelaps clethrionomydis, Laelaps traubi, and Laelaps turkestanicus) were collected from rodents residing at elevations $>900 \mathrm{~m}$ (Jameson 1965); therefore, it is not surprising that they were not discovered in the present study.

Among the four species, L. nuttalli was the most abundant, observed in all study sites, and collected from most small mammal species-except from the uncommon Callosciurus erythraeus and N. coninga (Tables 1 and 2). In Taiwan, L. nuttalli can reach an elevation of $900 \mathrm{~m}$ (Jameson 1965). L. nuttalli is also a common ectoparasite of commensal rodents in most parts of the world, including Africa, America, Asia, and the Indian Ocean and Pacific islands, being distributed from sea level to $>3000 \mathrm{~m}$ in elevation (Allred 1969). This species has also been found on bats (Ahamad et al. 2013). In the present study, Rickettsia species with the highest similarity to SFG rickettsiae have been detected in L. nuttalli which is also closely associated with commensal rodents that have frequent contact with humans, thus highlighting that the medical importance of this widely distributed mite species is worthy of further investigation. Similarly, L. echidninus is also a cosmopolitan ectoparasite of commensal rodents (Durden and Page 1991). Jameson (1965) only found this species on introduced or domestic Rattus rats but not on native rodents. Instead, we identified L. echidninus on seven host species, including $N$. coninga, which is native and endemic to Taiwan, thereby revealing a wider host range than previously considered. Likewise, $L$. sedlaceki was previously found only on N. coninga (Jameson 1965); however, it was also collected from another five host species in the current study (largely Rattus rats), which is 
similar to what has been observed in Borneo and New Guinea (Strandtmann and Mitchell 1963; $\mathrm{Ng}$ et al. 2017). In addition, species with the highest resemblance to SFG rickettsiae have also been identified in both L. echidninus and L. sedlaceki, once again underscoring the importance of assaying their competence for disease transmission. Lastly, L. myonyssognathus was the least common species in the present study, being found only on the abundant $R$. losea in western Taiwan, which is consistent with previous research (Jameson 1965); however, its hosts included at least nine shrew and rodent species in its distribution from East to South Asia (Mitchell 1968).

Over $75 \%$ of Laelaps mites were collected from $R$. losea, thus indicating that this common rodent is important in sustaining Laelaps mite populations. We have also identified $R$. losea as the primary host of ticks, chigger mites, and fleas in lowland Taiwan (Kuo et al. 2015b, c; Wang et al. 2020). Together, these studies demonstrate the prominent role of $R$. losea in supporting arthropod disease vectors in rural lowland Taiwan, which suggests that this species could be targeted when disease control measures are required. Interestingly, we also observed that $R$. exulans had a higher Laelaps mite burden similar to what has been reported in Indonesia (Durden and Page 1991) and Hawaii (Mitchell 1964). In Taiwan, $R$. exulans is an invasive species that is currently present only in Hualien (eastern Taiwan). This locally abundant rodent was found to serve only a minor role in supporting chigger mites due to its low chigger mite burden (Kuo et al. 2011). On the contrary, the higher Laelaps mite burden identified in this study suggests that the invasive $R$. exulans could be a competent host and its presence could augment the population of Laelaps mites, which subsequently increases the mite burden of other coexisting native rodents; such socalled "parasite spillback" effect can arise when invasion of a competent host increases the parasite load in native hosts by supporting a large number of local parasites (Kelly et al. 2009). Therefore, further validation of the importance of $R$. exulans in this context is recommended.

Acknowledgements This study was financially supported by Taiwan Centers for Disease Control (DOH97DC-2004, DOH98-DC-2012, DOH99-DC-2028). This article was subsidized by the National Taiwan Normal University (NTNU), Taiwan. All animal handling procedures were approved by the Taiwan Centers for Disease Control and adhered to Guideline for the Care and Use of Laboratory Animals established by the Taiwan Council of Agriculture.

\section{Compliance with ethical standards}

Conflict of interest The authors declare that they have no known competing financial interests or personal relationships that could have appeared to influence the work reported in this paper.

\section{References}

Ahamad M, Ibrahim H, Bujang MK, Mohd Sah SA, Mohamad N, Nor SM, Ahmad AH, Ho TM (2013) A survey of acarine ectoparasites of bats (Chiroptera) in Malaysia. J Med Entomol 50:140-146

Allred DM (1969) Mites of the genus Laelaps of New Guinea (Acari: Mesostigmata: Laelapidae). J Med Entomol 6:337-385

Allred DM (1970) Mites of the genus Laelaps from Viet Nam and Laos and a key to species of Indochina and Thailand. J Med Entomol 7:247-250

Bitam I, Dittmar K, Parola P, Whiting MF, Raoult D (2010) Fleas and flea-borne diseases. Int J Infect Dis 14:e667-e676

Cowling DW, Gardner IA, Johnson WO (1999) Comparison of methods for estimation of individual-level prevalence based on pooled samples. Prev Vet Med 39:211-225 
Dantas-Torres F, Chomel BB, Otranto D (2012) Ticks and tick-borne diseases: a One Health perspective. Trends Parasitol 28:437-446

Durden LA, Page BF (1991) Ectoparasites of commensal rodents in Sulawesi Utara, Indonesia, with notes on species of medical importance. Med Vet Entomol 5:1-7

Elliott I, Pearson I, Dahal P, Thomas NV, Roberts T, Newton PN (2019) Scrub typhus ecology: a systematic review of Orientia in vectors and hosts. Parasites Vector 12:513

Fuehrer HP, Igel P, Treiber M, Baumann TA, Riedl J, Swoboda P, Joachim A, Noedl H (2012) Ectoparasites of livestock, dogs, and wild rodents in the Chittagong Hill Tracts in southeastern Bangladesh. Parasitol Res 111:1867-1870

Guo XG, Speakman JR, Dong WG, Men XY, Qian TJ, Wu D, Qin F, Song WY (2013) Ectoparasitic insects and mites on Yunnan red-backed voles (Eothenomys miletus) from a localized area in southwest China. Parasitol Res 112:3543-3549

Jameson EW Jr (1965) The genus Laelaps (Acarica: Laelapidae) in Taiwan. J Med Entomol 2:41-53

Kelly DW, Paterson RA, Townsend CR, Poulin R, Tompkins DM (2009) Parasite spillback: a neglected concept in invasion ecology? Ecology 90:2047-2056

Krantz GW, Walter DE (2009) A Manual of Acarology. Texas Tech University Press, Lubbock

Kuo CC, Wang HC, Huang CL (2011) The potential effect of exotic pacific rats Rattus exulans on vectors of scrub typhus. J Appl Ecol 48:192-198

Kuo CC, Shu PY, Mu JJ, Wang HC (2015a) High prevalence of Rickettsia spp. infections in small mammals in Taiwan. Vector Borne Zoonotic Dis 15:13-20

Kuo CC, Shu PY, Mu JJ, Lee PL, Wu YW, Chung CK, Wang HC (2015b) Widespread Rickettsia spp. infections in ticks in Taiwan. J Med Entomol 52:1096-1102

Kuo CC, Lee PL, Chen CH, Wang HC (2015c) Surveillance of potential hosts and vectors of scrub typhus in Taiwan. Parasite Vector 8:611

Lin LG (1980) A Study on Mammals of Taiwan. Master Thesis. Department of Biology, Tunghai University, Taichung, Taiwan (In Chinese)

Martins-Hatano F, Gettinger D, Bergallo HG (2002) Ecology and host specificity of laelapine mites (Acari: Laelapidae) of small mammals in an Atlantic Forest area of Brazil. J Parasitol 88:36-41

Mitchell CJ (1964) Population structure and dynamics of Laelaps nuttalli Hirst and L. echidninus Berlese (Acarina: Laelaptidae) on Rattus rattus and R. exulans in Hawaii. J Med Entomol 1:151-153

Mitchell CJ (1968) Taxonomy, distribution, and host associations of Laelaps myonyssognathus Grochovskaya and Nguyen (Acarina: Laelapidae). J Med Entomol 5:93-99

Mitková K, Berthová L, Kalúz S, Kazimírová M, Burdová L, Kocianová E (2015) First detections of Rickettsia helvetica and $R$. monacensis in ectoparasitic mites (Laelapidae and Trombiculidae) infesting rodents in south-western Slovakia. Parasitol Res 114:2465-2472

Ng YL, Hamdan NE, Tuen AA, Mohd-Azlan J, Chong YL (2017) Co-infections of ectoparasite species in synanthropic rodents of western Sarawak, Malaysian Borneo. Trop Biomed 34:723-731

Paddock CD (2020) Rickettsialpox. In Hunter's tropical medicine and emerging infectious diseases (pp 594-598)

Parola P, Paddock CD, Raoult D (2005) Tick-borne rickettsioses around the world: emerging diseases challenging old concepts. Clin Microbiol Rev 18:719-756

Parola P, Paddock CD, Socolovschi C, Labruna MB, Mediannikov O, Kernif T et al (2013) Update on tickborne rickettsioses around the world: a geographic approach. Clin Microbiol Rev 26:657-702

Perlman SJ, Hunter MS, Zchori-Fein E (2006) The emerging diversity of Rickettsia. Proc R Soc Lond B Biol Sci 273:2097-2106

Radzijevskaja J, Kaminskienė E, Lipatova I, Mardosaitė-Busaitienė D, Balčiauskas L, Stanko M, Paulauskas A (2018) Prevalence and diversity of Rickettsia species in ectoparasites collected from small rodents in Lithuania. Parasit Vectors 11:375

Raoult D, Roux V (1997) Rickettsioses as paradigms of new or emerging infectious diseases. Clin Microbiol Rev 10:694-719

Reeves WK, Dowling AP, Dasch GA (2006) Rickettsial agents from parasitic dermanyssoidea (Acari: Mesostigmata). Exp Appl Acarol 38:181-188

Reif KE, Macaluso KR (2009) Ecology of Rickettsia felis: a review. J Med Entomol 46:723-736

Sergeant ESG (2018) EpiTools epidemiological calculators. Ausvet

Strandtmann RW, Mitchell CJ (1963) The laelaptine mites of the Echinolaelaps complex from the Southwest Pacific area (Acarina: Mesostigmata). Pac Insects 5:541-576

Tay ST, Mokhtar AS, Low KC, Mohd Zain SN, Jeffery J, Abdul Aziz N, Kho KL (2014) Identification of rickettsiae from wild rats and cat fleas in Malaysia. Med Vet Entomol 28(S1):104-108

Tsai YL, Chuang ST, Chang CC, Kass PH, Chomel BB (2010) Bartonella species in small mammals and their ectoparasites in Taiwan. Am J Trop Med Hyg 83:917-923 
Valiente Moro C, Chauve C, Zenner L (2005) Vectorial role of some dermanyssoid mites (Acari, Mesostigmata, Dermanyssoidea). Parasite 12:99-109

Vinarski MV, Korallo-Vinarskaya NP (2016) An annotated catalogue of the gamasid mites associated with small mammals in Asiatic Russia. The family Laelapidae s. str. (Acari: Mesostigmata: Gamasina). Zootaxa 4111:223-245

Wang HC, Lee PL, Kuo CC (2020) Fleas of shrews and rodents in rural lowland Taiwan. J Med Entomol 57:595-600

Wharton GW, Cross HF (1957) Studies on the feeding habits of three species of laelaptid mites. J Parasitol 43:45-50

Publisher's Note Springer Nature remains neutral with regard to jurisdictional claims in published maps and institutional affiliations. 